\title{
Fast On-line Solvent Extraction with the SISAK-3 Centrifuge System as a Test of Chemical Studies of the Elements 105 and 106
}

\author{
By B. Wierczinski ${ }^{1 *}$, J. Alstad ${ }^{2}$, K. Eberhardt ${ }^{1}$, B. Eichler ${ }^{3}$, H. Gäggeler ${ }^{3}$, G. Herrmann ${ }^{1}$, D. Jost ${ }^{3}$, \\ A. Nähler', M. Pense-Maskow ${ }^{1}$, A. V. R. Reddy ${ }^{1,4}$, G. Skarnemark ${ }^{5}$, N. Trautmannn ${ }^{1}$ and A. Türler ${ }^{3}$ \\ ' Institut für Kernchemie, Universität Mainz, D-55099 Mainz, Germany \\ ${ }^{2}$ Department of Chemistry, University of Oslo, N-0315 Oslo, Norway \\ ${ }^{3}$ Paul Scherrer Institut, CH-5232 Villigen, Switzerland \\ ${ }^{4}$ Bhabha Atomic Research Center, Trombay, Bombay 400085, India \\ 3 Department of Nuclear Chemistry, Chalmers University of Technology, S-41296 Göteborg, Sweden
}

(Received January 27, 1995)

\section{Rapid chemical separations / Solvent extraction on-line / Centrifuge system SISAK / Group 5 and 6 elements / Transactinide elements}

\begin{abstract}
The fast centrifuge system SISAK-3 has been applied to study in on-line experiments the chemical behavior of the homologs of Elements 105 and 106. Using $0.046 \mathrm{M}$ trioctylamine dissolved in Shellsol T, the Group 5 homologs of Element 105 and the Group 6 homologs of Element 106 can be extracted from an unbuffered $1.0 \mathrm{M} \alpha$-hydroxyisobutyric acid solution with yields between $60 \%$ and $100 \%$. Group 4 homologs of Element 104 and the lanthanides remain in the aqueous phase. Similar results were observed using lactic acid solutions.
\end{abstract}

\section{Introduction}

According to the systematics of the Periodic Table, the Elements 105 and 106, hahnium and seaborgium, should be located in the Groups 5 and 6, with tantalum and tungsten presumed to be their closest relatives. Recent studies of the chemical behavior of Element 105 show, however, that this element behaves more like niobium, but is distinctly different from tantalum [1-5]. These results may be explained by relativistic effects $[6,7]$ which should have an influence on the structure of the electron shells and, hence, on the chemical behavior of the heaviest elements. No chemical studies of Element 106 have been reported thus far. The half-life of the known isotope ${ }^{263} 106\left(T_{1 / 2}=0.9 \mathrm{~s}\right)$ is at the limit of what can be handled with present-day chemical techniques. Two recently discovered longer lived isotopes, ${ }^{265} 106\left(T_{1 / 2}=2-30 \mathrm{~s}\right)$ and ${ }^{266} 106$ $\left(T_{1 / 2}=10-30 \mathrm{~s}\right)$ [8] may improve the situation but low production rates are still a problem.

For investigations of the chemistry of transactinide elements, fast separation systems are essential. The centrifuge system SISAK-3 permits on-line solvent extraction experiments with nuclides having half-lives down to about one second $[9,10]$. It was the objective of the present investigation to explore the possibilities

\footnotetext{
* Present address: Nuclear Science Division, Lawrence Berkeley Laboratory, University of California, Berkeley, CA 94720 , USA.
}

of applying this system to study the chemistry of Elements 105 and 106. As a characteristic chemical property of the Group 5 and 6 elements, we chose the formation of their negatively charged complexes with $\alpha$-hydroxyisobutyric acid ( $\alpha$-HIB), as well as lactic acid in weakly acid solutions. For selective separation, we used the solvent extraction of these complexes by the liquid anion exchanger trioctylamine (TOA) dissolved in an inert organic solvent. The formation of negatively charged complexes with $\alpha$-HIB has been applied previously in cation exchange experiments [5] to show that Element 105 accompanies pentavalent niobium, tantalum, and protactinium in the elution from a cation exchange column, while tetravalent zirconium and trivalent europium are retained on the column. The formation of negatively charged complexes of molybdenum and tungsten with lactic acid (L) and other hydroxy acids is well documented. The species $\left[\mathrm{Me}^{\mathrm{vI}} \mathrm{O}_{2} \mathrm{~L}_{2}\right]^{2 \sim}$ is dominating in weakly acid solutions $[11,12]$. The lanthanides, the trivalent actinides and the Group 4 elements are present as positively charged complexes in weakly acid solutions of $\alpha$-HIB and lactic acid and are not expected to be coextracted into TOA.

After an exploration of this approach by conventional batchwise solvent extraction, on-line studies were carried out with the SISAK-3 system using the homologs $\mathrm{Zr}-\mathrm{Nb}$-Mo-La produced by fission and $\mathrm{Hf}-$ Ta-W made by $\alpha$-particle induced reactions; La served as an analog element for the trivalent actinides. In these experiments, the subsequent steps of a radiochemical procedure were performed continuously: (i) production of the model elements by nuclear reactions, (ii) transport from the target area to the SISAK-3 setup, (iii) chemical separation by solvent extraction, and (iv) inspection of the two final, organic and aqueous phases by $\gamma$-ray spectroscopy.

\section{Experimental}

Radioactive tracers. For the batch experiments, the following tracer activities were produced by neutron capture reactions in respective metal salts irradiated 
in a neutron flux of $7 \times 10^{11} \mathrm{~cm}^{-2} \mathrm{~s}^{-1}$ in the Mainz TRIGA reactor: $17-\mathrm{h}{ }^{97} \mathrm{Zr}, 40-\mathrm{h}{ }^{140} \mathrm{La}, 42-\mathrm{d}{ }^{181} \mathrm{Hf}$, and $114-\mathrm{d}{ }^{1828} \mathrm{Ta}$. In addition, $58-\mathrm{s}{ }^{97 \mathrm{~m}} \mathrm{Nb}$ and $74-\mathrm{min}{ }^{978} \mathrm{Nb}$ were obtained carrier-free by $\beta^{-}$-decay of ${ }^{97} \mathrm{Zr}$. In the SISAK experiments carrier-free fission products of neutron-irradiated ${ }^{239} \mathrm{Pu}$ were applied using the nuclides 7.1-s ${ }^{100} \mathrm{Zr}, 15-\mathrm{s}{ }^{99} \mathrm{~N} \mathrm{Nb}, 36-\mathrm{s}{ }^{105} \mathrm{Mo}$, and 41-s ${ }^{144} \mathrm{La}$ as most characteristic tracers of the lighter homologs. In one experiment the fission products were mixed with carrier-free $27-\mathrm{d}{ }^{233} \mathrm{~Pa}$ produced by neutron capture in thorium and subsequent $\beta^{-}$-decay and with carrier-containing ${ }^{181} \mathrm{Hf}$ and ${ }^{182 \mathrm{~g}} \mathrm{Ta}$. Carrier-free tracers of the heavier homologs, 51-min ${ }^{177 m}{ }^{2} \mathrm{Hf}, 16-\mathrm{min}$ ${ }^{182 \mathrm{~m}} \mathrm{Ta}, 2.2-\mathrm{h}{ }^{177} \mathrm{~W}$, and $6.4-\mathrm{min}{ }^{179 \mathrm{~m}} \mathrm{~W}$, were obtained by irradiation of hafnium and tungsten targets with $49 \mathrm{MeV} \alpha$-particles (average particle beam intensity $0.5 \mu \mathrm{A})$ at the Philips cyclotron of PSI Villigen.

Batch experiments. Batch experiments were carried out by shaking in a separatory funnel for five seconds an aqueous solution spiked with tracers and an equal volume of the organic solution containing the extracting agent. The $\mathrm{pH}$-value of the aqueous phase was adjusted with $\mathrm{HCl}$ or $\mathrm{NH}_{4} \mathrm{OH}$. After phase separation, the extraction yields were determined by measuring aliquots of each phase by $\gamma$-ray spectroscopy using $\mathrm{Ge}$ (HPGe) or $\mathrm{Ge}(\mathrm{Li})$ detectors (resolution 1.8 and $3.0 \mathrm{keV}$ FWHM at $1333 \mathrm{keV}$, respectively).

SISAK-3 experiments. The fast centrifuge system SISAK-3 applied in the on-line extraction experiments is described elsewhere in detail $[9,13]$. Two different construction materials were used, namely Ti passivated with Pd or polyetheretherketone (PEEK). Both materials are resistant to the solutions used in our experiments.

The reaction products were transported from the target chamber to the SISAK-3 system by means of a $\mathrm{N}_{2} / \mathrm{KCl}$-gas jet in Mainz or a $\mathrm{He} / \mathrm{KCl}$-gas jet at PSI. The nuclear reaction products attached to aerosols in the gas jet were dissolved by means of a stationary mixer in an aqueous phase heated to about $70^{\circ} \mathrm{C}$. The gaseous reaction products and the carrier gas were removed in a degasser with an inner volume of $0.1 \mathrm{ml}$. The aqueous phase was then contacted with an organic solution containing the extracting agent and the mixed phases were fed into the centrifuge, inner volume $0.3 \mathrm{ml}$, and separated in about $0.1 \mathrm{~s}$. Flow rates were typically about $0.5 \mathrm{ml} \mathrm{s}^{-1}$ for both phases. The extraction yields were determined from $\gamma$-ray measurements performed using HPGe and $\mathrm{Ge}(\mathrm{Li})$ detectors on the outgoing phases in teflon capillaries $(2 \mathrm{~mm}$ i.d.) or in teflon cells of various volumes, depending on half-life and count rate of the nuclides. Counting times were typically 15 minutes.

\section{Results and discussion}

The experiments covered the following range of parameters:

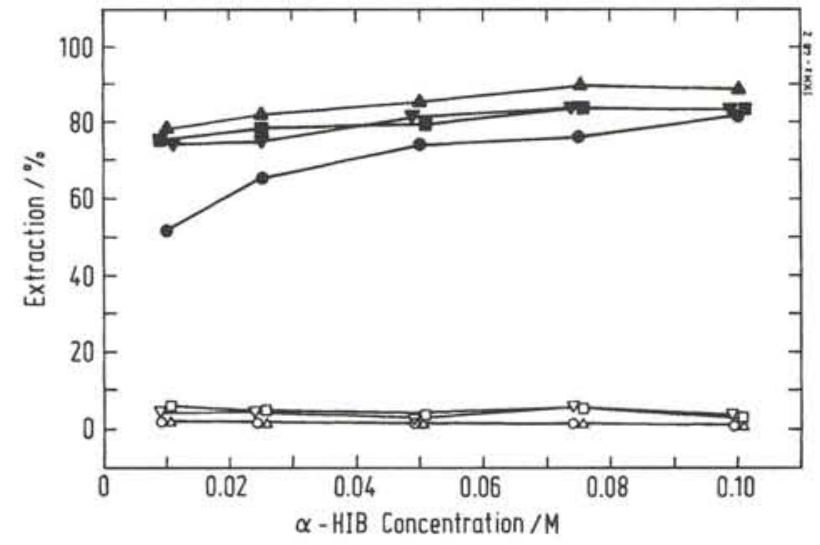

Fig. 1. Extraction yields of hafnium (open symbols) and tantalum (filled symbols) in batch experiments at various concentrations of $\alpha$-hydroxyisobutyric acid ( $\alpha$-HIB) in the aqueous phase, with the following concentrations of trioctylamine (TOA) in the organic solvent Shellsol T: $0.023 \mathrm{M}, \Delta \boldsymbol{\Delta} 0.058 \mathrm{M}$, $\nabla \nabla 0.115 \mathrm{M}, \square 0.172 \mathrm{M}$.

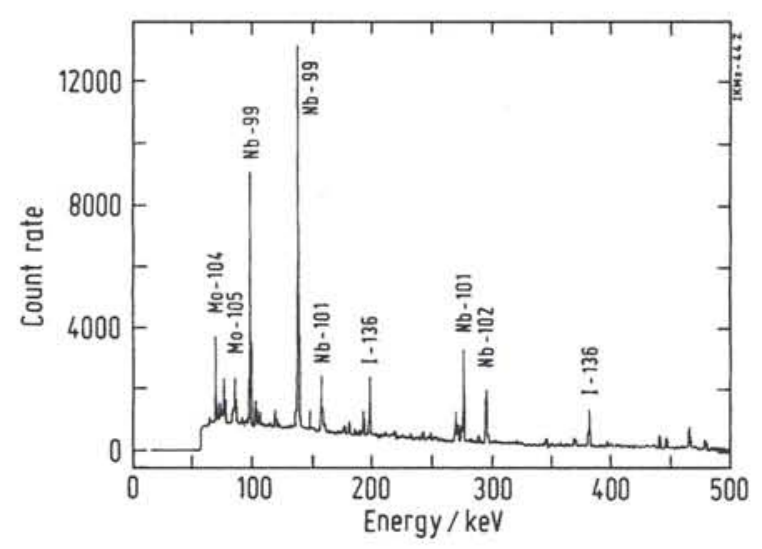

Fig. 2. Example of the $\gamma$-ray spectra measured on-line in SISAK experiments; organic phase after solvent extraction of a fission product mixture with $0.023 \mathrm{M}$ TOA/Shellsol $\mathrm{T}$ from $1.0 \mathrm{M}$ $a$ - $\mathrm{HIB}$ at $\mathrm{pH} 1.8$.

- $\alpha$-hydroxyisobutyric acid ( $\alpha$-HIB) solutions at various $\mathrm{pH}$-values ( 0 to 4$)$ and concentrations $(0.01 \mathrm{M}$ to $5.0 \mathrm{M})$,

- 1.0 M lactic acid solutions at $\mathrm{pH}$-values from 1 to 3.5 ,

- trioctylamine (TOA) dissolved in Shellsol T $(0.011-0.17 \mathrm{M})$ as the organic solvent.

As an example for the batch experiments, Fig. 1 shows the extraction yields of $\mathrm{Hf}$ and $\mathrm{Ta}$ at various concentrations of $\alpha$-HIB and TOA. We note an increase of the yield for Ta up to $90 \%$ at the highest $\alpha$-HIB and TOA concentrations applied, whereas the yield for Hf remains below $5 \%$ at all concentrations. The same trend of high extraction yield is found for $\mathrm{Nb}$, whereas $\mathrm{Zr}$ and also $\mathrm{La}$ are extracted very little or below the detection limit.

In a series of SISAK- 3 experiments with the lighter homologs, $\alpha$-HIB-concentrations ranged from $0.1 \mathrm{M}$ to $5.0 \mathrm{M}$ and TOA-concentrations from $0.011 \mathrm{M}$ to $0.114 \mathrm{M}$. The $\mathrm{pH}-\mathrm{value}$ of the aqueous phases was 


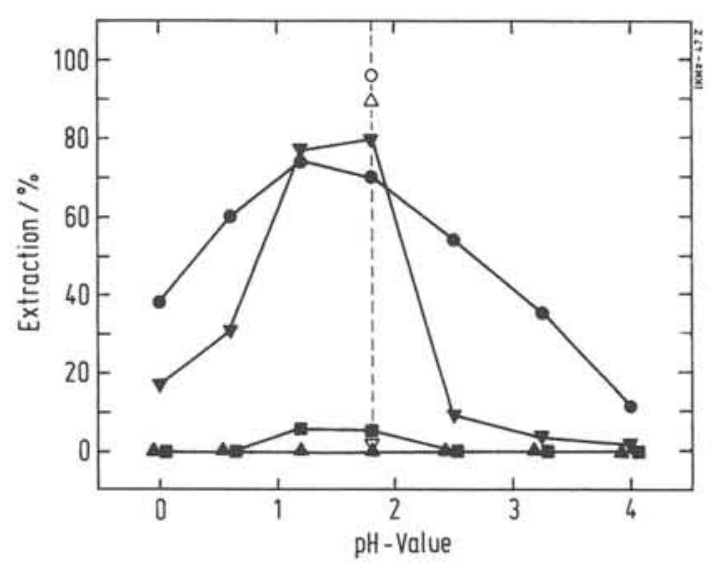

Fig. 3. Extraction yields of zirconium ( $\mathbf{\square})$, niobium $(\bullet)$, molybdenum $(\boldsymbol{\nabla})$, lanthanum $(\boldsymbol{\Delta})$, hafnium $(\nabla)$, tantalum $(O)$, and protactinium $(\Delta)$ from $1.0 \mathrm{M} \alpha$-HIB at various $\mathrm{pH}$-values with $0.046 \mathrm{M} \mathrm{TOA} /$ Shellsol $\mathrm{T}$ in SISAK on-line experiments. Dashed line: optimum pH-value (1.8).

fixed at $\mathrm{pH} 1.0$. With $0.023 \mathrm{M}$ TOA, the highest extraction yields for $\mathrm{Nb}$ and Mo are obtained at an $\alpha$ HIB-concentration of $1.0 \mathrm{M}$. Under these conditions, $\mathrm{Zr}$ and $\mathrm{La}$ remain in the aqueous phase. Figure 2 shows an example of the $\gamma$-ray spectra observed in the organic phase during an on-line experiment. We note a clear enrichment of niobium $\left(15-\mathrm{s}{ }^{99} \mathrm{Nb}, 7.1-\mathrm{s}{ }^{101} \mathrm{Nb}\right.$, 4.3-s ${ }^{102} \mathrm{Nb}$ ) and Mo activities (60-s ${ }^{104} \mathrm{Mo}, 36-\mathrm{s}^{105} \mathrm{Mo}$ ) from the complex fission product mixture, with 47-s ${ }^{136}$ I being the only strong contaminant, as is usually found in SISAK solvent extraction procedures.

In further experiments with the lighter homologs, the $\mathrm{pH}$-value of the $\alpha$-HIB-solutions was varied from 0 to 4 . The highest extraction yields are obtained for an unbuffered $1.0 \mathrm{M} \alpha$-HIB-solution which has an $\mathrm{pH}$ value of 1.8 and with $0.046 \mathrm{M}$ TOA $(2 \mathrm{Vol} . \%)$ as the organic solution, as can be seen in Fig. 3. Mo is extracted to $80 \%, \mathrm{Nb}$ to $70 \%, \mathrm{Zr}$ to $\leq 5 \%$, whereas $\mathrm{La}$ is found only in the aqueous phase. At these conditions carrier-free $\mathrm{Pa}$ and neutron-activated $\mathrm{Ta}$ and $\mathrm{Hf}$ were added to the aqueous phase. The extraction yields are $88 \%$ for $\mathrm{Pa}, 96 \%$ for $\mathrm{Ta}$, and $2 \%$ for Hf. These experiments have been performed with $\mathrm{Ti}$ as well as with PEEK centrifuges and the results were the same. It is interesting to note that $\mathrm{Pa}$ follows $\mathrm{Nb}$ and $\mathrm{Ta}$ in their high extraction yields. As in many other chemical properties, $\mathrm{Pa}$ behaves like a Group 5 element where it would be located in an extrapolation of the Periodic Table beyond Ac, if the actinide concept would not be taken into account.

In another series of SISAK-3 experiments the heavier Group 4, 5 and 6 elements were used in carrier-free form. As Fig. 4 depicts, extraction from $1.0 \mathrm{M}$ $\alpha$-HIB solutions showed nearly $100 \%$ yield for Ta at $\mathrm{pH}$-values from 1.0 to 2.0 and almost $80 \%$ for $\mathrm{W}$ from $\mathrm{pH}$-values 1.0 to 1.5 . Hf is not extracted in the $\mathrm{pH}$ range studied. The best results for $\mathrm{Ta}$ were again obtained with an unbuffered solution of $1.0 \mathrm{M} \alpha$-HIB as aqueous and $0.046 \mathrm{M}$ TOA/Shellsol $\mathrm{T}$ as organic

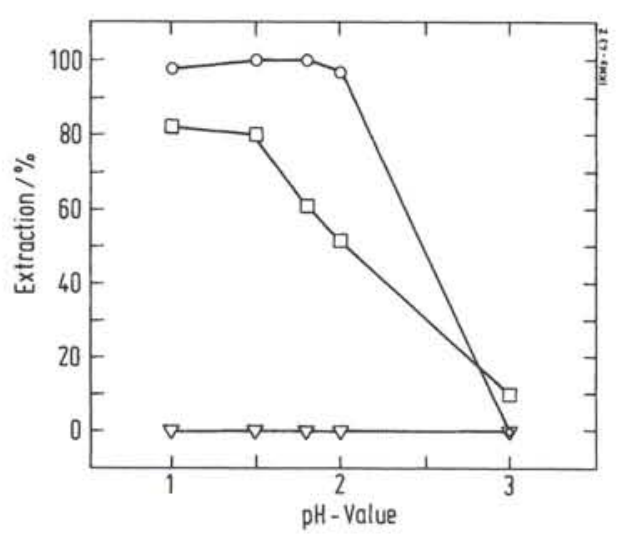

Fig. 4. Extraction yields of carrier-free hafnium $(\nabla)$, tantalum $(O)$, and tungsten $(\square)$ from $1.0 \mathrm{M} \alpha$-HIB at various $\mathrm{pH}$-values with $0.046 \mathrm{M}$ TOA/Shellsol T in SISAK on-line experiments.

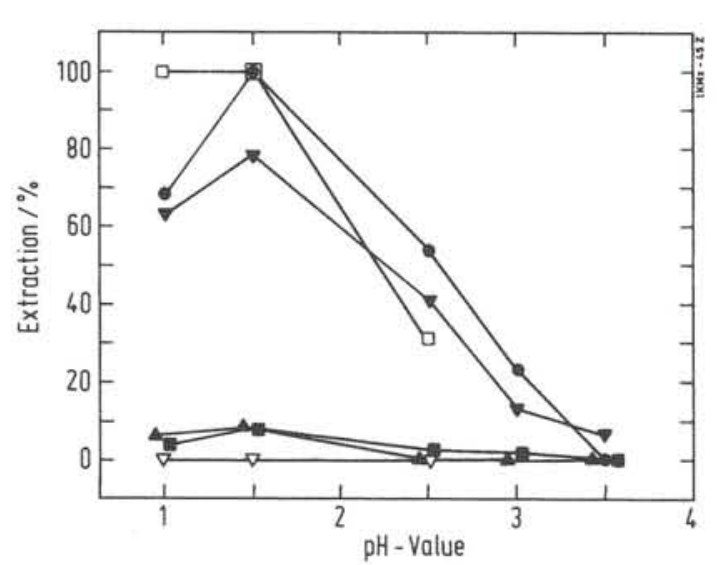

Fig. 5. Extraction yields of zirconium (ם), niobium (-), molybdenum $(\mathbf{\nabla})$, lanthanum $(\boldsymbol{\Delta})$, hafnium $(\nabla)$, and tungsten ( $\square$ ) from $1.0 \mathrm{M}$ lactic acid at various $\mathrm{pH}$-values with $0.046 \mathrm{M}$ TOA/Shellsol T in SISAK on-line experiments.

phase, whereas for $\mathrm{W}$ a slightly lower $\mathrm{pH}$-value is preferable.

With lactic acid instead of $\alpha$-HIB as the aqueous solution similar extraction yields, Fig. 5, are found. Again the highest yields result for an unbuffered solution of $1.0 \mathrm{M}$ lactic acid (pH 1.5). Mo is extracted to $78 \%, \mathrm{Nb}$ and $\mathrm{W}$ to $100 \%, \mathrm{Zr}, \mathrm{La}$ and $\mathrm{Hf}$ only to a small extent.

With the heavier homologs, several experiments were performed under slightly modified conditions. Addition of dodecanol to the aqueous phase improves the phase separation without any effect on extraction yields. The use of toluene as diluent for TOA (replacing Shellsol T) did not change the extraction yields of $\mathrm{Ta}$ and $\mathrm{W}$ but did increase slightly the extraction of Hf.

\section{Conclusions}

According to our experiments, the homologs of the Elements 105 and 106 are efficiently extracted into TOA from unbuffered $1.0 \mathrm{M}$ solutions of $\alpha$-HIB or lactic acid on time scales fast enough for application to 
nuclides with half-lives of a few seconds. The fact that the Group 5 and Group 6 elements are extracted simultaneously is not considered to be a problem because Element 105 will not be formed in heavy-ion fusion reactions producing Element 106 and vice versa. Thus, the method presented here is one of the possible approaches to study the solution chemistry of Element 106 for the first time and to further investigate the chemical properties of Element 105.

\section{Acknowledgements}

We are grateful to the operating crews of the Mainz nuclear reactor and the PSI cyclotron for numerous irradiations. One of us (A.V.R.R.) is indebted for a fellowship under the German-Indian Exchange Program. This work was sponsored by the German Bundesminister für Forschung und Technologie (BMFT) under Contract No. 03HE2MAI. Financial support from the Norwegian Council for Sciences and $\mathrm{Hu}-$ manities and the Swedish Natural Science Research Council is acknowledged.

\section{References}

1. Gregorich, K. E., Henderson, R. A., Lee, D. M., Nurmia, M. J., Chasteler, R. M., Hall, H. L., Bennett, D. A., Gannett, C. M., Chadwick, R. B., Leyba, J. D., Hoffman, D. C., Herrmann, G.: Radiochim. Acta 43, 223 (1988).

2. Kratz, J. V., Zimmermann, H. P., Scherer, U. W., Schädel, M., Brüchle, W., Gregorich, K. E., Gannett, C. M., Hall, H. L., Henderson, R. A., Lee, D. M., Leyba, J. D., Nurmia, M. J., Hoffman, D. C., Gäggeler, H., Jost, D., Baltensperger, U., Nai-Qi, Y., Türler, A., Lienert, C.: Radiochim. Acta 48, 121 (1989).
3. Gober, M. K., Kratz, J. V., Zimmermann, H. P., Schädel, M., Brüchle, W., Schimpf, E., Gregorich, K. E., Türler, A., Hannink, N. J., Czerwinski, K. R., Kadkhodayan, B., Lee, D. M., Nurmia, M. J., Hoffman, D. C., Gäggeler, H., Jost, D., Kovacs, J., Scherer, U. W., Weber, A.: Radiochim. Acta 57, 77 (1992).

4. Schädel, M., Brüchle, W., Schimpf, E., Zimmermann, H. P., Gober, M. K., Kratz, J. V., Trautmann, N., Gäggeler, H., Jost, D., Kovacs, J., Scherer, U. W., Weber, A., Gregorich, K. E., Türler, A., Czewinski, K. R., Hannink, N. J., Kadkhodayan, B., Lee, D. M., Nurmia, M. J., Hoffman, D. C.: Radiochim. Acta 57, 85 (1992).

5. Gäggeler, H. W., Jost, D. T., Kovacs, J., Scherer, U. W., Weber, A., Vermeulen, D., Türler, A., Gregorich, K. E., Henderson, R. A., Czerwinski, K. R. Kadkhodayan, B., Lee, D. M., Nurmia, M. J., Hoffman, D. C., Kratz, J. V., Gober, M. K., Zimmermann, H. P., Schädel, M., Brüchle, W., Schimpf, E., Zvara, I.: Radiochim. Acta 57, 93 (1992).

6. Pershina, V., Fricke, B., Kratz, J. V., Ionova, G. V.: Radiochim. Acta 64, 37 (1994).

7. Kratz, J. V.: J. Alloys Compounds 213/214, 20 (1994).

8. Lazarev, Yu. A., Lobanov, Yu. V., Oganessian, Yu. Ts., Utyonkov, V. K., Abdullin, F. Sh., Buklanov, G. V., Gikal, B. N., Iliev, S., Mezentsev, A. N., Polyakov, A. N., Sedykh, I. M., Shirokovsky, I. V., Subbotin, V. G., Sukhov, A. M., Tsyganov, Yu. S., Zhuchko, V. E., Lougheed, R. W., Moody, K. J., Wild, J. F., Hulet, E. K., McQuaid, J. H.: Phys. Rev. Lett. 73, 624 (1994).

9. Persson, H., Skarnemark, G., Skålberg, M., Alstad, J., Liljenzin, J. O., Bauer, G., Haberberger, F., Kaffrell, N., Rogowski, J., Trautmann, N.: Radiochim. Acta 48, 177 (1992).

10. Altzitzoglou, T., Rogowski, J., Skålberg, M., Alstad, J., Herrmann, G., Kaffrell, N., Skarnemark, G., Talbert, W., Trautmann, N.: Radiochim. Acta 51, 145 (1990).

11. Caldeira, M. M., Ramos, M. L., Gil, V. M.: Canad. J. Chem. 65, 827 (1987).

12. Cruywagen, J. J., Krüger, L., Rohwer, E. A.: J. Chem. Soc. Dalton Trans. 1993, 105.

13. Alstad, J., Skarnemark, G., Haberberger, F., Herrmann, G., Nähler, A., Pense-Maskow, M., Trautmann, N.: J. Radioanal. Nucl. Chem. 189, 133 (1995). 